\title{
Comparison of Doppler Flow Tei-Indexes With Pulmonary Artery Thermodilution Measurement of Cardiac Output in an Experimental Porcine Model
}

\author{
J. KOBR ${ }^{1}$, V. TŘEŠKA ${ }^{2}$, J. MOLÁČEK ${ }^{2}$, V. KUNTSCHER ${ }^{2}$, V. LIŠKA ${ }^{2}$, Z. SLAVÍK ${ }^{3}$ \\ ${ }^{1}$ Department of Paediatrics - Pediatric Intensive Care Unit and ${ }^{2}$ Department of Surgery, Charles \\ University in Prague, Faculty of Medicine in Pilsen, Czech Republic, ${ }^{3}$ Department of Paediatrics - \\ Intensive Care Unit, The Royal Brompton and Harefield Hospital NHS Trust, London, United \\ Kingdom
}

Received March 31, 2010

Accepted December 2, 2010

On-line March 14, 2011

\begin{abstract}
Summary
The objective of our study was to compare Doppler echocardiography imaging with pulmonary artery thermodilution measurement during mechanical ventilation. Total 78 piglets (6 weeks old, average weight $24 \mathrm{~kg}$, under general anesthesia) were divided into 4 groups under different cardiac loading conditions (at rest, with increased left ventricular afterload, with increased right ventricular preload, and with increased afterload of both heart ventricles). At 60 and $120 \mathrm{~min}$ the animals were examined by echocardiography and simultaneously pulmonary artery thermodilution was used to measure cardiac output. Tei-indexes data were compared with invasively monitored hemodynamic data and cardiac output values together with calculated vascular resistance indices. A total of 224 parallel measurements were obtained. Correlation was found between values of right Tei-index of myocardial performance and changes in right ventricular preload $(p<0.05)$ and afterload $(p<0.01)$. Significant correlation was also found between left index values and changes of left ventricular preload $(p<0.001)$, afterload $(p<0.001)$, stroke volume $(p<0.01)$, and cardiac output $(p<0.01)$. In conclusion, echocardiographic examination and determination of the global performance selectively for the right and left ventricle can be recommended as a suitable non-invasive supplement to the whole set of methods used for monitoring of circulation and cardiac performance.
\end{abstract}

\section{Key words}

Myocardial performance - Tei-index • Pulmonary artery

thermodilution $\bullet$ Cardiac output • Piglets

\section{Corresponding author}

Jiri Kobr, Charles University in Prague, Faculty of Medicine in Pilsen, Alej Svobody 80, 30460 Pilsen, Czech Republic. E-mail: kobr@fnplzen.cz

\section{Introduction}

Cardiopulmonary interaction plays an essential role in critically ill pediatric patients. Accurate assessment of cardiac output and myocardial function has been considered vital in the successful treatment of any such patients. There are several techniques for monitoring cardiac output in seriously ill patients. The use of thermodilution for cardiac output measurements via in-dwelling pulmonary arterial catheter is considered one of the most reliable methods of haemodynamic monitoring in pediatric patients. However, its invasive nature is not without inherent risks (Takano 1997, Carmosino et al. 2007).

Non-invasive methods of cardiovascular functional monitoring are therefore particularly appealing in children. The Tei-indexes of myocardial performance (IMP) has been demonstrated to fulfill criteria as a noninvasive, easily obtainable, and reproducible tool for myocardial performance assessment in both adult and pediatric patients (Williams et al. 2000, Pratap et al. 2004, Lavine et al. 2008). The technique is based on Doppler derived time intervals within the cardiac cycle and used to assess global, systolic and diastolic 
myocardial function. It also allows for separate assessment of the left and right ventricular function and its increasing value represents myocardial dysfunction (Tei et al. 1995).

Given the persistent controversy about load dependence of IMP (LaCorte et al. 2003, Teschima et al. 2007, Murphy et al. 2007), we compared hemodynamic parameters achieved using invasive monitoring with values of myocardial performance indexes in an experimental setting.

\section{Materials and Methods}

The study was conducted with the approval of a multidisciplinary institutional ethics committee in an EU accredited experimental center of the Faculty of Medicine of Charles University in Pilsen, Czech Republic. Respecting the principles of Helsinki Declaration this study was part of an ongoing experimental studies.

Seventy-eight clinically healthy piglets (aged 6 weeks, mean weight $24 \mathrm{~kg}$ with range between $18-27 \mathrm{~kg}$, male to female ratio 1:3) anesthetized, endotracheally intubated, catheterized and divided into 4 groups: Control Group A $(n=34)$ included spontaneously breathing animals without surgical intervention nor changes in hemodynamics. After completing the measurements in this control group, the animals were generally anesthetized, mechanically ventilated with neuromuscular block, and divided into two groups according to further surgical interventions: Group B animals $(n=17)$ formed the hemodynamic model of animals with cross clamping of the abdominal aorta above the origin of renal arteries (Treska et al. 2003), and Group C $(n=17)$ comprised of animals with partial occlusion of the portal bed via right portal vein embolization (Liska et al. 2009). In the normal course of events the high volume of venous blood from the digestive tract of unpaired organs arises through the portal circulation to the liver on the basis of a pressure gradient. Acute occlusion of half of the entire portal venous bed causes early portal hypertension and transient changes in regional hemodynamics. Immediate adaptation after surgery leads to a reduction in liver flow lasting several hours, and conversely increases flow through the natural porto-systemic venous connections into the lower vena cava (Sinderman et al. 1978, Sheen et al. 2000). Temporary increase in-flow in the lower vena cava was used to create an experimental hemodynamic model of increased right ventricle preload and diastolic filling (Karunanithi et al. 1992, Khan et al. 2009). Group D $(n=44)$ animals underwent abdominal aortic tight banding 3 weeks before study commencement (Molacek et al. 2009), and were ventilated by high tidal volume strategy. The combination of flow-limiting abdominal aorta and increasing pressure in the chest created a hemodynamic model of the increase afterload of the both heart ventricles.

The internal jugular vein was cannulated for central venous access using the Seldinger percutaneous technique and a Swan-Ganz thermodilution pulmonary catheter was introduced. The femoral artery was used for direct arterial blood pressure monitoring via the arterial catheter. The animals were examined by echocardiography to acquire data for Tei-indexes calculations, invasively monitored hemodynamic data were recorded, and thermodilution technique was used to parallel measure cardiac output via pulmonary artery catheter.

\section{General anesthesia and ventilator support}

Premedication was given by intramuscular administration of atropine $0.07 \mathrm{mg} / \mathrm{kg}$ and azaperone $5.0 \mathrm{mg} / \mathrm{kg}$. General anesthesia was induced by intravenous administration of thiopental $10 \mathrm{mg} / \mathrm{kg}$ and all animals were orotracheally intubated. Combined general anesthesia was maintained by intravenous ketamine 1.5-3.0 $\mathrm{mg} / \mathrm{kg}$ or fentanyl $0.5-1.0 \mathrm{microg} / \mathrm{kg}$ with azaperone $3.0-4.0 \mathrm{mg} / \mathrm{kg}$ and peripheral muscle paralysis by pancuronium $0.1-0.2 \mathrm{mg} / \mathrm{kg}$ (Jacson et al. 2007).

Animals in Group A were breathing spontaneously with continuous positive airway pressure support at $2 \mathrm{cmH}_{2} \mathrm{O}$ and $\mathrm{FiO}_{2}$ 0.21. Animals in Groups B, $\mathrm{C}$, and $\mathrm{D}$ were mechanically ventilated using a servoventilator (Siemens Elema900C, Germany) in pressure controlled mode with the following settings: $\mathrm{P}_{\text {insp }}$ $15 \mathrm{cmH}_{2} 0$, rate 24 breath/min, PEEP $6 \mathrm{cmH}_{2} \mathrm{O}$, I:E 0.7 , $\mathrm{FiO}_{2} 0.21$ in Groups B, C. Group D settings were $\mathrm{P}_{\text {insp }}$ $30 \mathrm{cmH}_{2} 0$, rate 30 breath/min., PEEP $0 \mathrm{cmH}_{2} \mathrm{O}$, I:E 1.0 , $\mathrm{FiO}_{2} 0.21$.

\section{Study protocol}

Experimental work in all piglets utilized tracheal intubation and establishing invasive entry under general anesthesia. Following a 60-min recovery period the first measurement reading was taken and echocardiographic imaging performed (time-1). After a further sixty minutes, all measurements were repeated (time-2). 
Echocardiographic assessment and Tei indexes calculations

A transthoracic echocardiogram was performed using 3.5-5.0 MHz probe (Sonoline Siem, Siemens; Germany). A two-dimensional echocardiogram and pulse wave Doppler were used in apical four-chamber view to acquire data from blood flow through atrioventricular and in a left parasternal view of the semilunar valves, respectively. Care was taken to align the transducer beam as closely as possible to the blood flow axis. Doppler signals for the left and right ventricular valves were not acquired simultaneously. No angle correction was made. Doppler and ECG tracings were recorded and stored digitally.

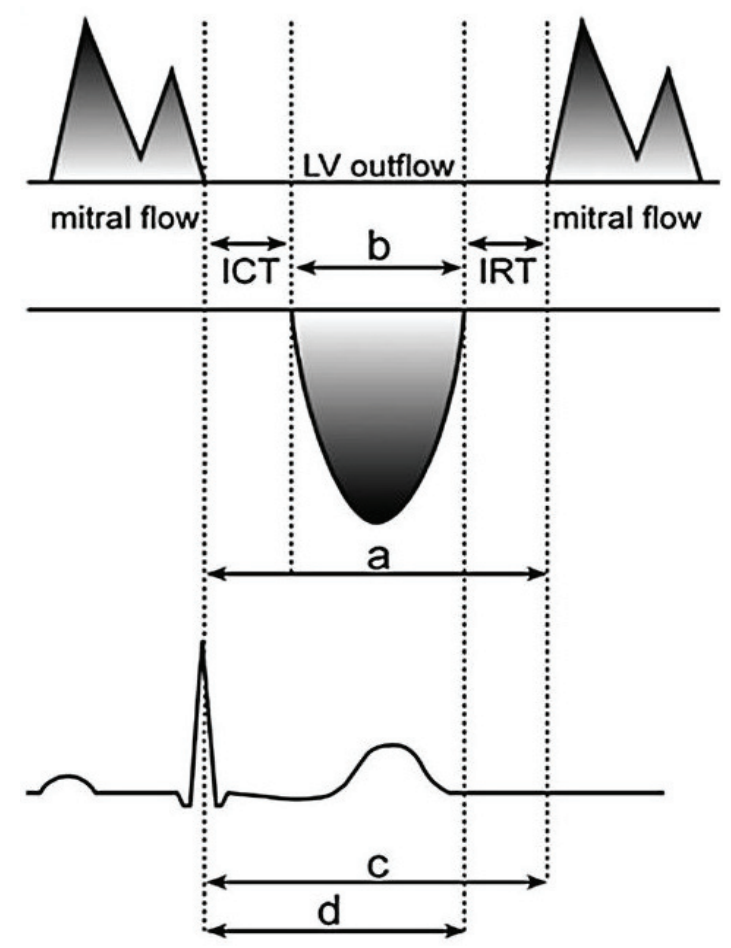

$$
\mathrm{MPI}=\frac{(a-b)}{b}=\frac{(I C T+I R T)}{E T}
$$

Fig. 1. Schema for measurements of Doppler time intervals and calculations. Interval $a$, the interval between cessation and onset of the tricuspid or mitral inflow (AVCO); interval $b$, the ejection time (ET) of right or left ventricular outflow; interval $c$, the interval between the $\mathrm{R}$ wave and the cessation of right or left ventricular outflow; interval $d$, the interval between the $\mathrm{R}$ wave and the onset of mitral inflow; MPI, myocardial performance index; ICT, isovolumic contraction time (obtained by subtracting IRT from $a-b)$; IRT, isovolumic relaxation time $(c-d)$

The blood flow time intervals were measured by taking the three most distinct Doppler trace in a frozen template. The time interval from the cessation to the onset of mitral or tricuspid inflow (AVCO) was measured. This interval is equal to the sum of isovolumic contraction time, ejection time, and isovolumic relaxation time. Left and right ventricular ejection time (ET) was measured in the ascending aorta or main pulmonary artery just above the corresponding valve. Myocardial performance index was then calculated using formula (AVCO - ET) / ET selectively for the right (RIMP) and left (LIMP) heart ventricle (LaCorte et al. 2003, Eidem et al. 1998). Diagram representing the measurement and calculation of MPI figures are documented in Figure 1 (Pattoneri et al. 2007). Real display pulse Doppler flow in the pulmonary ejection time measurement in experimental animals in our study is shown in Figure 2.

Thus the calculated value was divided by the current value of the R-R interval of simultaneously recorded electrocardiogram to exclude the impact of variations in heart rate on the measurement result. This method was used to calculate the myocardial performance index for each of the three measurements. The average value of these three indices was stored in a database. This data was used for statistical processing.

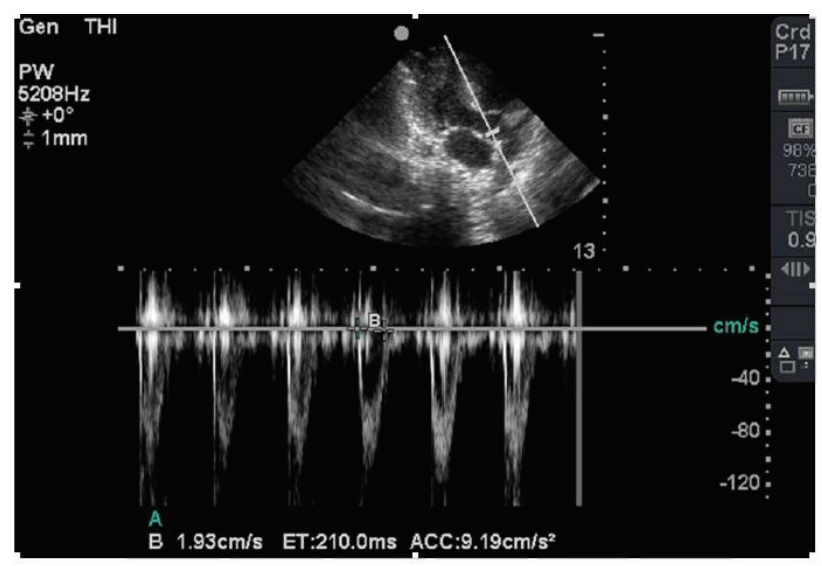

Fig. 2. Real pulse Doppler flow measurements in the pulmonary ejection time. The top figure shows the morphology of the right heart, right ventricular outflow tract, the semilunar valve and the pulmonary trunk. The bottom diagram shows the pulse Doppler flow in the pulmonary artery and crosses marked with the value of right ventricular ejection time.

Measurement of cardiac output and hemodynamic data acquisition

Cardiac output was measured by intermittent pulmonary artery thermodilution. Under ultrasound guidance a Swan-Ganz thermodilution catheter was positioned in the pulmonary artery. The average temperature of $38.5^{\circ} \mathrm{C}$ measured in the pulmonary artery allowed for adequate thermal difference with the test 
solution (0.9 M sodium chloride at $\left.21^{\circ} \mathrm{C}\right)$. Standard technique was used to assess cardiac output by rapid injection of test solution into proximal port of pulmonary artery catheter and subsequent temperature monitoring at the catheter tip (Takano et al. 1997). Moreover, no fluid replacement bolus or any other therapeutic intervention was performed at the time of all data acquisition.

The following hemodynamic data were acquired, calculated and recorded: heart rate, mean central venous pressure, right heart ventricle pressure, pulmonary arterial pressure, pulmonary arterial occlusive (capillary wedge) pressure, mean arterial pressure (MAP), stroke volume, cardiac output and cardiac index, systemic vascular resistance (MAP-CVP/CO), pulmonary arteriolarvascular resistance (PAP-PAoP/CO). Body surface area of animals was calculated using the following Meehe's formula: $0.087 \mathrm{x}$ weight / $0.66\left(\mathrm{~m}^{2}\right)$ (LaCorte et al. 2003). Each parameter was expressed as mean value from the five consecutive measurements in 30 second intervals.

Table 1. Data values obtained in groups and the differences between Groups B, C, D and control Group A ( $n=244)$.

\begin{tabular}{|c|c|c|c|c|c|c|c|}
\hline \multirow{2}{*}{ Variables } & $\begin{array}{c}\text { Group A } \\
n=68\end{array}$ & $\begin{array}{c}\text { Group B } \\
\mathbf{n}=34\end{array}$ & \multirow{2}{*}{$\mathbf{P}<$} & $\begin{array}{c}\text { Group C } \\
\mathbf{n}=34\end{array}$ & \multirow{2}{*}{$\mathbf{P}<$} & $\begin{array}{c}\text { Group D } \\
\mathbf{n}=\mathbf{8 8}\end{array}$ & \multirow{2}{*}{$\mathbf{P}<$} \\
\hline & $\begin{array}{c}\text { Mean } \pm \text { SD } \\
(95 \% \text { CI })\end{array}$ & $\begin{array}{c}\text { Mean } \pm \text { SD } \\
(95 \% \text { CI })\end{array}$ & & $\begin{array}{c}\text { Mean } \pm \text { SD } \\
(95 \% \text { CI })\end{array}$ & & $\begin{array}{c}\text { Mean } \pm \text { SD } \\
(95 \% \text { CI })\end{array}$ & \\
\hline$R I M P$ & $\begin{array}{c}0.20 \pm 0.03 \\
(0.18-0.21)\end{array}$ & $\begin{array}{c}0.23 \pm 0.02 \\
(0.22-0.24)\end{array}$ & 0.05 & $\begin{array}{c}0.24 \pm 0.03 \\
(0.23-0.25)\end{array}$ & 0.01 & $\begin{array}{c}0.24 \pm 0.03 \\
(0.23-0.25)\end{array}$ & 0.01 \\
\hline$L I M P$ & $\begin{array}{c}0.28 \pm 0.02 \\
(0.27-0.29)\end{array}$ & $\begin{array}{c}0.38 \pm 0.06 \\
(0.36-0.40)\end{array}$ & 0.05 & $\begin{array}{c}0.38 \pm 0.06 \\
(0.36-0.40)\end{array}$ & 0.01 & $\begin{array}{c}0.41 \pm 0.07 \\
(0.39-0.43)\end{array}$ & 0.01 \\
\hline$H R$ & $\begin{array}{c}158.00 \pm 19.40 \\
(148.07-165.13)\end{array}$ & $\begin{array}{c}161.02 \pm 19.42 \\
(150.07-163.45)\end{array}$ & NS & $\begin{array}{c}160.05 \pm 19.12 \\
(149.22-173.30)\end{array}$ & NS & $\begin{array}{c}161.11 \pm 19.60 \\
(145.07-179.10)\end{array}$ & NS \\
\hline$C V P$ & $\begin{array}{c}1.81 \pm 2.17 \\
(1.00-2.00)\end{array}$ & $\begin{array}{c}2.80 \pm 2.61 \\
(3.31-4.91)\end{array}$ & 0.05 & $\begin{array}{c}5.60 \pm 2.42 \\
(4.81-6.50)\end{array}$ & 0.01 & $\begin{array}{c}3.60 \pm 2.33 \\
(2.90-4.31)\end{array}$ & 0.01 \\
\hline$R V P$ & $\begin{array}{c}9.04 \pm 1.87 \\
(8.03-9.01)\end{array}$ & $\begin{array}{c}9.45 \pm 1.74 \\
(9.23-12.33)\end{array}$ & 0.05 & $\begin{array}{c}14.43 \pm 3.04 \\
(13.43-15.41)\end{array}$ & 0.01 & $\begin{array}{c}14.12 \pm 2.30 \\
(13.41-14.81)\end{array}$ & 0.01 \\
\hline$P A P$ & $\begin{array}{c}16.02 \pm 3.13 \\
(14.02-17.82)\end{array}$ & $\begin{array}{c}16.50 \pm 2.53 \\
(14.70-17.80)\end{array}$ & NS & $\begin{array}{c}17.21 \pm 5.30 \\
(15.31-19.07)\end{array}$ & 0.05 & $\begin{array}{c}18.04 \pm 4.73 \\
(14.90-20.20)\end{array}$ & NS \\
\hline$P A o P$ & $\begin{array}{c}6.91 \pm 5.87 \\
(7.04-10.01)\end{array}$ & $\begin{array}{c}10.64 \pm 2.33 \\
(9.82-11.31)\end{array}$ & 0.01 & $\begin{array}{c}13.53 \pm 2.44 \\
(12.72-14.33)\end{array}$ & 0.01 & $\begin{array}{c}12.60 \pm 2.72 \\
(11.81-13.40)\end{array}$ & 0.01 \\
\hline$M A P$ & $\begin{array}{c}75.52 \pm 4.30 \\
(73.12-78.04)\end{array}$ & $\begin{array}{c}75.80 \pm 3.74 \\
(72.81-78.41)\end{array}$ & NS & $\begin{array}{c}75.22 \pm 3.30 \\
(72.61-77.30)\end{array}$ & $\mathrm{NS}$ & $\begin{array}{c}74.74 \pm 3.50 \\
(71.80-78.12)\end{array}$ & NS \\
\hline$S V$ & $\begin{array}{c}18.03 \pm 2.50 \\
(16.04-19.02)\end{array}$ & $\begin{array}{c}17.93 \pm 2.84 \\
(15.61-19.51)\end{array}$ & NS & $\begin{array}{c}15.21 \pm 2.62 \\
(14.04-17.31)\end{array}$ & 0.01 & $\begin{array}{c}16.04 \pm 2.60 \\
(15.70-17.91)\end{array}$ & 0.01 \\
\hline $\mathrm{CO}$ & $\begin{array}{c}2.91 \pm 0.98 \\
(1.95-3.02)\end{array}$ & $\begin{array}{c}2.66 \pm 0.83 \\
(2.02-3.01)\end{array}$ & NS & $\begin{array}{c}1.94 \pm 1.01 \\
(1.46-2.72)\end{array}$ & 0.01 & $\begin{array}{c}2.04 \pm 1.10 \\
(1.64-2.77)\end{array}$ & 0.01 \\
\hline$C I$ & $\begin{array}{c}1.34 \pm 0.30 \\
(1.11-1.53)\end{array}$ & $\begin{array}{c}1.25 \pm 0.28 \\
(1.03-1.44)\end{array}$ & NS & $\begin{array}{c}0.64 \pm 0.37 \\
(0.52-0.77)\end{array}$ & 0.01 & $\begin{array}{c}0.71 \pm 0.34 \\
(0.60-0.81)\end{array}$ & 0.01 \\
\hline$M A P-C V P$ & $\begin{array}{c}73.71 \pm 2.13 \\
(74.31-76.29)\end{array}$ & $\begin{array}{c}74.22 \pm 1.78 \\
(73.90-75.73)\end{array}$ & NS & $\begin{array}{c}69.13 \pm 3.8 \\
(67.81-70.54)\end{array}$ & 0.01 & $\begin{array}{c}72.03 \pm 3.34 \\
(71.01-73.05)\end{array}$ & 0.05 \\
\hline$S V R$ & $\begin{array}{l}1580.03 \pm 680.31 \\
(1830.0-1920.2)\end{array}$ & $\begin{array}{l}1595.07 \pm 480.01 \\
(1490.4-1975.0)\end{array}$ & NS & $\begin{array}{l}2435.12 \pm 130.20 \\
(2210.2-2570.1)\end{array}$ & 0.01 & $\begin{array}{l}2370.11 \pm 392.08 \\
(2260.3-2550.1)\end{array}$ & 0.01 \\
\hline$P V R$ & $\begin{array}{c}404.17 \pm 52.23 \\
(378.34-420.22)\end{array}$ & $\begin{array}{c}409.02 \pm 58.32 \\
(382.11-437.40)\end{array}$ & NS & $\begin{array}{c}440.01 \pm 82.24 \\
(411.02-469.17)\end{array}$ & 0.01 & $\begin{array}{c}429.01 \pm 77.31 \\
(405.10-452.44)\end{array}$ & 0.01 \\
\hline
\end{tabular}

RIMP, myocardial performance index of right ventricle; LIMP, myocardial performance index of left ventricle; HR, heart rate (beat/min); CVP, mean central venous pressure $(\mathrm{mmHg}) ; \mathrm{RVP}$, mean right ventricle pressure $(\mathrm{mmHg}) ; \mathrm{PAP}$, mean pulmonary artery pressure $(\mathrm{mmHg})$; PAoP, mean pulmonary artery occlusive pressure $(\mathrm{mmHg})$; MAP, mean artery pressure $(\mathrm{mmHg}) ; \mathrm{SV}$, stroke volume (ml); CO, cardiac output $(\mathrm{l} / \mathrm{min}) ; \mathrm{CI}$, cardiac index $\left(\mathrm{I} / \mathrm{min} / \mathrm{m}^{2}\right)$; MAP-CVP, difference of mean systemic pressures $(\mathrm{mmHg}) ; \mathrm{SVR}$, systemic vascular resistance (dyn.sec/cm $\left.{ }^{5}\right) ;$ PVR, pulmonary vascular resistance $\left(\right.$ dyn. $\left.\mathrm{sec} / \mathrm{cm}^{5}\right) ; \mathrm{NS}$, not significant; $P<$, values $\mathrm{P}$ 


\section{Statistical analysis}

Parametric data were expressed as mean, standard deviation (SD) and $95 \%$ confidence interval (95\% CI). Pearson's analysis and polynominal regression was used to compare the data obtained. Collinearity between variables was tested prior to modelling by computing the correlation of estimates, with a $R^{2}>0.5$ considered to be significant. For qualitative analysis of accuracy of the variables reference interval dispersion, the linearity, reproducibility agreement were used (Bland et al. 1986). $P$ values $<0.05$ were considered statistically significant. All data were analyzed using statistical software (Analyze-it211 Software Ltd.).

\section{Results}

A total of 224 parallels data sets including data on myocardial performance indexes, hemodynamics and cardiac output measurements were acquired. Echocardiographic measurements of myocardial performance indices (IMP; $\mathrm{n}=224)$ showed excellent reproducibility $(p<0.01)$ and acceptable diversity $(p=0.097)$. The files of all data and differences in quality between the groups were not statistically significant.

Differences between the values of data obtained in the time-1, time- 2 of study in groups were not statistically significant. A summary of all data values obtained in the groups and the differences between Groups B, C, D and control Group A are listed in Table 1.

In all ventilated (Groups B, C and D) RIMP, LIMP, CVP and PAoP were higher compared with spontaneously breathing animals of Group A. In Groups $\mathrm{C}$ and D the values of HR, SV, CO, CI, PVR and SVR were higher compared with Group A, while there were no differences between Group B and Group A.

Correlations of the RIMP and LIMP with the values of standard hemodynamic parameters in individual Groups B, C and D are listed in Table 2. The set of all data obtained in the study was used for the overall correlation between RIMP and LIMP and hemodynamic parameters. The results of these correlations are presented in Table 3.

In spontaneously breathing piglets (Group A) LIMP values correlated only with the SVR $\left(R^{2}=0.69\right.$; $p<0.01$ ), but in ventilated animals (Groups B, C and D) correlated with the PAoP, SVR, CO, and MAP-CVP. RIMP values in Groups C, D correlated with the CVP, RVP, MAP, CVP and PVR, but in Group B only with PVR and RVP. When processing all data obtained $(n=224)$ values RIMP correlated directly with the CVP and PVR. Values LIMP correlated directly with the PAoP, SVR, and indirectly with SV, CO, and MAP.

Table 2. Correlations of myocardial performance indexes with standard hemodynamic parameters in the groups ventilated animals $(n=120)$.

\begin{tabular}{|c|c|c|c|c|c|c|c|}
\hline \multirow{2}{*}{$\begin{array}{l}\text { Dependent } \\
\text { variables }\end{array}$} & \multirow{2}{*}{$\begin{array}{l}\text { Independent } \\
\text { variables }\end{array}$} & \multicolumn{2}{|c|}{$\begin{array}{c}\text { Group B } \\
\mathbf{n}=34\end{array}$} & \multicolumn{2}{|c|}{$\begin{array}{c}\text { Group C } \\
\mathbf{n}=\mathbf{3 4}\end{array}$} & \multicolumn{2}{|c|}{$\begin{array}{c}\text { Group D } \\
\mathbf{n}=\mathbf{8 8}\end{array}$} \\
\hline & & $\mathbf{R}^{2}$ & $\mathbf{P}<$ & $\mathbf{R}^{2}$ & $\mathbf{P}<$ & $\mathbf{R}^{2}$ & $\mathbf{P}<$ \\
\hline \multirow[t]{4}{*}{ RIMP } & $P V R$ & 0.78 & 0.01 & 0.87 & 0.001 & 0.72 & 0.01 \\
\hline & $C V P$ & 0.35 & NS & 0.83 & 0.001 & 0.69 & 0.01 \\
\hline & $M A P-C V P$ & 0.28 & NS & 0.82 & 0.001 & 0.67 & 0.05 \\
\hline & $R V P$ & 0.88 & 0.001 & 0.75 & 0.01 & 0.81 & 0.001 \\
\hline \multirow[t]{6}{*}{$L I M P$} & $S V R$ & 0.84 & 0.001 & 0.68 & 0.05 & 0.75 & 0.01 \\
\hline & PAoP & 0.75 & 0.01 & 0.89 & 0.001 & 0.82 & 0.001 \\
\hline & $S V$ & 0.66 & 0.05 & 0.59 & 0.05 & 0.31 & NS \\
\hline & $\mathrm{CO}$ & 0.78 & 0.01 & 0.81 & 0.01 & 0.76 & 0.01 \\
\hline & $M A P$ & 0.38 & NS & 0.35 & NS & 0.90 & 0.001 \\
\hline & $M A P-C V P$ & 0.57 & 0.05 & 0.60 & 0.05 & 0.61 & 0.05 \\
\hline
\end{tabular}

RIMP, myocardial performance index of right ventricle; LIMP, myocardial performance index of left ventricle; HR, heart rate (beat/min); $\mathrm{CVP}$, mean central venous pressure $(\mathrm{mmHg})$; RVP, mean right ventricle pressure (mmHg); PAP, mean pulmonary artery pressure $(\mathrm{mmHg}) ; \mathrm{PAoP}$, mean pulmonary artery occlusive pressure ( $\mathrm{mmHg}) ; \mathrm{MAP}$, mean artery pressure (mmHg); SV, stroke volume (ml); CO, cardiac output (I/min); MAP-CVP, difference of mean systemic pressures $(\mathrm{mmHg}) ; \mathrm{SVR}$, systemic vascular resistance (dyn.sec/cm $\left.{ }^{5}\right)$; PVR, pulmonary vascular resistance (dyn.sec/ $\mathrm{cm}^{5}$ ); NS, not significant; $R^{2}$, multiple Pearson's residual index; $p<$, level of significance 
Table 3. Correlations of myocardial performance indexes with standard hemodynamic parameters in the set of all data obtained $(n=244)$.

\begin{tabular}{|c|c|c|c|c|}
\hline Dependent variables & Independent variables & $95 \%$ CI interval & $\mathbf{R}^{2}$ & $\mathbf{P}<$ \\
\hline \multirow[t]{6}{*}{$R I M P$} & $P V R$ & 0.57 to 0.75 & 0.67 & 0.01 \\
\hline & $R V P$ & 0.13 to 0.42 & 0.28 & NS \\
\hline & $C V P$ & 0.27 to 0.53 & 0.51 & 0.05 \\
\hline & $M A P-C V P$ & -0.46 to -0.17 & 0.32 & NS \\
\hline & $P A o P$ & 0.21 to 0.48 & 0.35 & NS \\
\hline & $C O$ & -0.37 to -0.07 & 0.23 & NS \\
\hline \multirow[t]{7}{*}{ LIMP } & $S V R$ & 0.77 to 0.87 & 0.86 & 0.001 \\
\hline & $P A o P$ & 0.64 to 0.79 & 0.72 & 0.001 \\
\hline & $S V$ & -0.53 to -0.19 & 0.62 & 0.01 \\
\hline & $C O$ & -0.73 to -0.54 & 0.64 & 0.01 \\
\hline & $M A P$ & -0.86 to -0.75 & 0.82 & 0.001 \\
\hline & $M A P-C V P$ & -0.42 to -0.13 & 0.28 & NS \\
\hline & $P V R$ & 0.11 to 0.40 & 0.26 & NS \\
\hline
\end{tabular}

RIMP, myocardial performance index of right ventricle; LIMP, myocardial performance index of left ventricle; CVP, mean central venous pressure $(\mathrm{mmHg})$; RVP, mean right ventricle pressure $(\mathrm{mmHg}) ;$ PAoP, mean pulmonary artery occlusive pressure (mmHg); PVR, pulmonary vascular resistance (dyn. $\left.\mathrm{sec} / \mathrm{cm}^{5}\right)$; MAP-CVP, difference of mean systemic pressures $(\mathrm{mmHg})$; $\mathrm{CO}$, cardiac output $(\mathrm{I} / \mathrm{min})$; $\mathrm{SVR}$, systemic vascular resistance $\left(\mathrm{dyn} . \mathrm{sec} / \mathrm{cm}^{5}\right)$; MAP, mean artery pressure $(\mathrm{mmHg}) ; \mathrm{NS}$, not significant; $R^{2}$, multiple Pearson's residual index; $p<$, level of significance

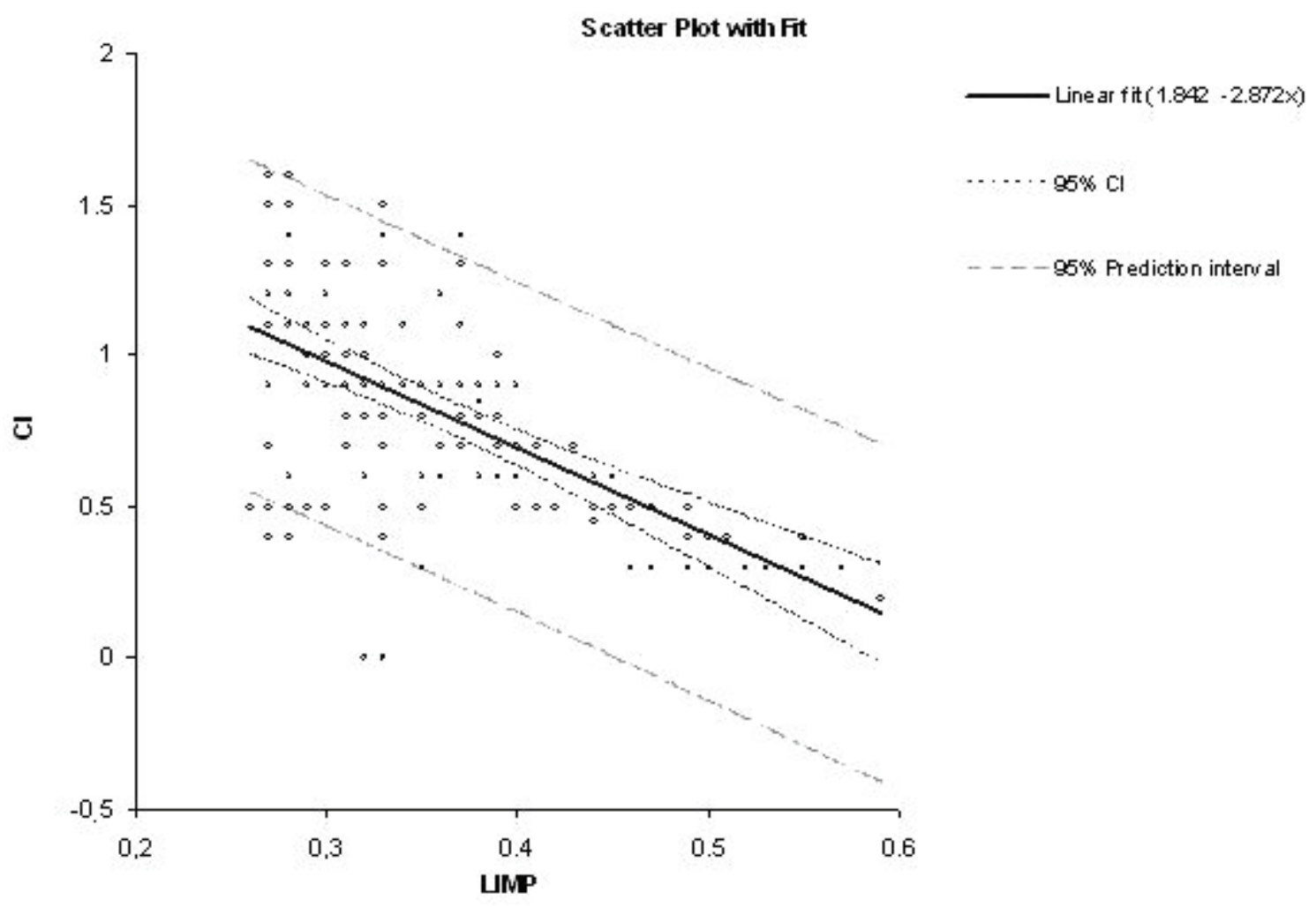

Fig. 3. Chart polynominal regression data of the left myocardial performance index vs cardiac index. The " $x$ " axis of the graph are plotted the data values left myocardial performance index and on the axis " $y$ " values of cardiac index data. 


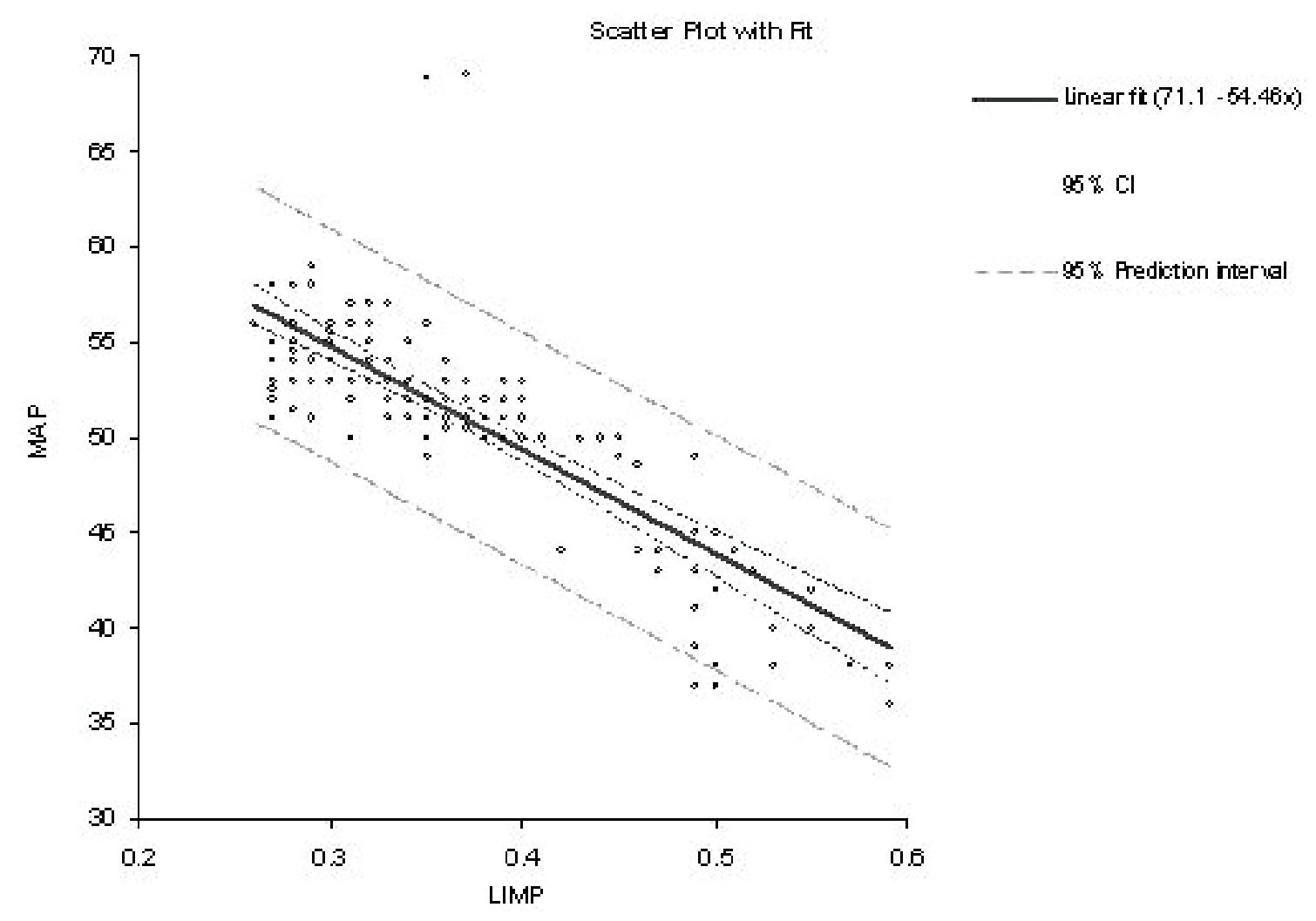

Fig. 4. Chart polynominal regression data of the left myocardial performance index vs mean arterial pressure. The "x" axis of the graph are plotted the data values left myocardial performance index and on the axis " $y$ " values of mean arterial pressure data.

After analyzing the entire data set $(n=224)$ polynominal regression revealed significant correlations between the values of LIMP versus CI $(\mathrm{p}<0.001)$ and Limp vs. MAP $(p<0.001)$. Graphical representation of those regressions are given in Figures 3 to 4 .

\section{Discussion}

Echocardiographic index of global myocardial performance has been used in non-invasive assessment of cardiac function for more than 10 years (Takano et al. 1997). Wide experience was gained with its use both in experimental (LaCorte et al. 2003, Teshima et al. 2007, Treska et al. 2003, Liska et al. 2009, Molacek et al. 2009, Cheung et al. 2004, Hori et al. 2007) and adult clinical practice (Lavine et al. 2008, Tei et al. 1995 and 1997, Murphy et al. 2007), respectively. It also appears to be a useful prognostic tool in adult patients with dilated cardiomyopathy (Koga et al. 2008, Dujardin et al. 1998), anthracyclin induced myocardial toxicity (Peltier et al. 2002), chronic lung disease (Senju et al. 2007), amyloidosis (Tei et al. 1996), and Chagas disease (Burges et al. 2002). This index of myocardial performance has been validated in paediatric patients with various congenital heart defects (Williams et al. 2000, Eidem et al. 1998 and 2000, Yacoub et al. 2003), and with pulmonary hypertension (Pratap et al. 2004). It has been found useful in the acute setting of paediatric cardiac intensive care as well (Harada et al. 2002, Patel et al. 2009). Controversy has persisted about its load independence. In their original description of the index, found it independent of the degree of mitral valve regurgitation. They subsequently found the index correlated closely with parameters of systolic and diastolic myocardial function measured invasively (Takano et al. 1997, Tei et al. 1996). However, further experimental testing of the index against acute changes in both preload and afterload conveyed some evidence about significant impact of these changes on the index values (Hori et al. 2007). Results from our experimental study show a correlation between indices of myocardial performance for the right ventricle and its invasively measured preload (central venous pressure) and afterload (pulmonary vascular resistance). Left ventricular index of myocardial performance also correlated with its preload (pulmonary arterial occlusion pressure) and afterload (systemic vascular resistance). Both indices then inversely correlated with cardiac output. These results support load dependence of the index. It has to be stressed that all data in our study 
were obtained in an acute setting of experimental kidney transplantation or liver surgery. It is perhaps not surprising that myocardial function as assessed by global myocardial performance index closely mirrors acute changes in ventricular loading conditions and afterload in particular. Experimental studies of Cheung et al. (2004) and Lavine et al. $(2006,2008)$ are of particular interest here. They all show dependence of the index on loading conditions in pigs and dogs, respectively. Positive and negative inotropic agents were used to assess the index sensitivity to altered myocardial function. Interesting results were obtained showing improvement of the index values (lower values) in the setting of mildly chronically decreased left ventricular function with acute administration of dobutamine infusions (2.0-2.5 $\mu \mathrm{g} / \mathrm{kg} / \mathrm{min})$ or following one month of digoxin treatment (Duggal et al. 2005). No such improvement was observed with dobutamine administration $(5.0 \mu \mathrm{g} / \mathrm{kg} / \mathrm{min})$ in pigs with normal left ventricular function despite improved $\mathrm{dP} / \mathrm{dt}$ in the study of Cheung et al. Any such results and their extrapolation into clinical human physiology have to be treated with caution as inter-species and even intra-species differences are likely (Cheung et al. 2004, Patel et al. 2009). Nevertheless the index of myocardial performance being dependent on loading conditions follows changes in myocardial function and it appears to have predictive value mainly in myocardial dysfunction. This probably reflects changes in isovolumic contraction time and ejection time most likely to be affected by disease states leading to myocardial systolic dysfunction and increased afterload. Treatment interventions altering myocardial systolic function and afterload with concomitant shortening of isovolumic contraction time and lengthening of ejection time will lead to improved values of the index (Lavine et al. 2006).

At our centre we obviously prefer minimally invasive techniques. In critically ill children we asses the global performance of each ventricle. Over the last approximately ten years we have had excellent experience with echocardiography. Repeated echocardiographic evaluation and calculations of Tei-indices with shortening fraction in combination with continuous monitoring of systemic pressures we checked the effectiveness of pharmacological circulatory support. Quality testing is for all methods of monitoring hemodynamics depend on the hands-on investigator experience. The basic levels of cardiologic morphological orientation, measurement and control of the sonographic apparatus may be achieved over an intensive course lasting several days. However, good technique using invasive thermo-dilution methods does take considerably longer. At our PICU, $75 \%$ of physicians are trained in echocardiography, whilst only $5 \%$ are experienced in thermo-dilution techniques. It was a logical step for us to scientifically confirm that the global preferred trend of minimally invasive techniques in determining cardiac performance, are comparable to the so-called gold standard in monitoring haemodynamics via a pulmonary catheter.

The authors of this work are aware that echocardiographic imaging does have its limitations, most of which are investigator dependent (e.g. angle of spread of the doppler wave). Measurement of the time interval between the opening and closing of the atrioventricular valves (AVCO), however, is not investigator dependent. This measurement is imprecise during tachycardia where this interval is significantly shortened. We feel that any potential inaccuracies of this method are counterbalanced when the same investigator performs all the measurements in each subject. The clinical assessment of each subject does not depend upon absolute values, but rather the trend of the measured parameters.

Additional limitations of study may include the fact that the study duration took place over 6 years. As the fundamental aim of the study was to achieve the greatest amount of data from a very large number of haemodynamically compromised animals, it was a logistical problem to achieve this in a shorter period of time. As the investigator, apparatus and experimental conditions throughout the entire length of the study remained constant, we feel that the end result is minimally influenced by bias. Echocardiographic cardiac imaging in piglets is hampered by the morphological uniqueness of their chest anatomy, not least by the narrow intercostals spaces. Echocardiography, introduction of pulmonary artery catheter and all measurements were performed by the same investigator in all test animals.

In the statistical processing of large amounts of data $(n=224)$ was more accurate calculation of correlation and assessment different than the processing of data in each group.

All the above limitations do not detract from the importance of the Tei-index as a non-invasive, easily obtainable, and reproducible tool for assessment of biventricular myocardial performance in the setting of experimental work and clinical intensive care. Based on our experience and the experience of others serial measurements of this index are likely to be a valuable tool in close monitoring of cardiovascular function in critically ill patients. 


\section{Conflict of Interest}

There is no conflict of interest.

\section{Acknowledgements}

Mr. RNDr. František Šefrna, PhD. has been a consultantstatistics of our work and include it with gratitude for active cooperation. The study was supported by Research Project of Charles University in Prague, Faculty of Medicine in Pilsen No. MSM 0021160819-6096, grants the Ministry of Health of the Czech Republic IGA no. NA/7653-3, NR/7909-3, and grant of the Charles University GA no. 82/2000/C/LFP.

\section{References}

BLAND JM, ALTMAN DG: Statistical methods for assessing agreement between two methods of clinical measurement. Lancet 1: 307-310, 1986.

BURGES MI, MOGULKOC M, BRIGHT-THOMAS RJ, BISHOP P, EGAN JJ, RAY SG: Comparison of echocardiographic markers of right ventricular function in determining prognosis in chronic lung disease. $J \mathrm{Am}$ Soc Echocardiogr 15: 633-639, 2002.

CARMOSINO M, FRIESEN RH, DORAN A, IVY DD: Perioperative complications in children with pulmonary hypertension undergoing noncardiac surgery or cardiac catheterization. Anesth Analg 104: 521-527, 2007.

CHEUNG MMH, SMALLHORN JF, REDINGTON AN, VOGEL M: The effects of changes in loading conditions and modulation of inotropic state on the myocardial performance index: comparison with conductance catheter maesurements. Eur Heart J 25: 2238-2242, 2004.

DUGGAL B, PRATAP U, SLAVIK Z, KAPLANOVA J, MACRAE D: Milrinone and low cardiac output following cardiac surgery in infants: is there a direct myocardial effect? Pediatr Cardiol 26: 642-645, 2005.

DUJARDIN KS, TEI C, YEO TC, HODGE DO, ROSSI A, SEWARD JB: Prognostic value of a Doppler index combining systolic and diastolic performance in idiopathic-dilated cardiomyopathy. Am J Cardiol 82: 1071-1076, 1998.

EIDEM BW, TEI C, O’LEARY P: Nongeometric quantitative assessment of right and left ventricular function: myocardial performance index in normal children and patients with Ebstein anomaly. J Am Soc Echocardiogr 11: 849-856, 1998.

EIDEM BW, O'LEARY P, TEI C, SEWARD JB: Usefulness of the myocardial performance index for assessing right ventricular function in congenital heart disease. Am J Cardiol 86: 654-658, 2000.

HARADA K, TAMURA M, TOYONO M, YASUOKA K: Effect of dobutamine on a Doppler echocardiographic index of combined systolic and diastolic performance. Pediatr Cardiol 23: 613-617, 2002.

HORI Y, UECHI M, INDOU A: Changes in the myocardial performance index during dobutamine administration in anaesthetised cats. Am J Vet Res 68: 385-388, 2007.

JACSON PG, COCKROFT P: Analgesia, anesthesia, and surgical procedures in the pig. In: Handbook of Pig Medicine. PG JACKSON, P COCKROFT (eds), Saunders / Elsevier, Cambridge, 2007, pp 30-241.

KARUNANITHI MK, MICHNIEWICZ J, COPELAND SE, FENELEY MP: Right ventricular preload recruitable stroke work, end-systolic pressure-volume, and dP/dTmax-end-diastolic volume relations compared as index of right ventricular contractile performance in conscious dogs. Circ Res 70: 1169-1179, 1992.

KHAN AN, MACDONALD S, SHEEN AJ, TAM CL, SHERLOCK D, AL-KHATTAB Y: Portal vein thrombosis. http://emedicine.medscape.com/article/373009, 2009.

KOGA S, IKEDA S, URATA J, KOHNO S: Effect of nasal continuous positive airway pressure in men on global left ventricular myocardial performance in patients with obstructive sleep apnea syndrome. Am J Cardiol 101: 1796$1800,2008$.

LACORTE JC, CABRERIZA SE, RABKIN DG, PRINZ BF, COKU L, WEINBERGER A, GERSONY WM, SPOTNITZ HM: Correlation of the Tei index with invasive measurement of ventricular function in a porcine model. $J$ Am Soc Echocardiogr 16: 442-447, 2003.

LAVINE SJ: Effect of changes in contractility on the index of myocardial performance in the dysfunctional left ventricle. Cardiovasc Ultrasound 4: 45, 2006.

LAVINE SJ, CONETTA DA: Comparison of the effect of pressure loading on left ventricular size, systolic and diastolic function in canines with left ventricular dysfunction with preserved and reduced ejection fraction. Cardiovasc Ultrasound 6: 57-67, 2008. 
LISKA V, SLOWIK P, EGGENHOFER E, TRESKA V, RENNER P, POPP FC, MIRKA H, KOBR J, SYKORA R, SCHLITT HJ, HOLUBEC L, CHLUMSKA A, SKALICKY T, MATEJOVIC M, DAHLKE MH: Intraportal injection of porcine multipotent mesenchymal stromal cells augments liver regeneration after portal vein embolization. In Vivo 23: 229-236, 2009.

MOLACEK J, TRESKA V, KOBR J, CERTIK B, SKALICKY T, KUNTSCHER V, KRIZKOVA V: Optimalization of the model of abdominal aortic aneurysm. Experiment in an animal model. $J$ Vasc Res 46: 1-5, 2009.

MURPHY GS, MARYMONT JH, SZOKOL JW, AVRAM MJ, VENDER JS: Correlation of the myocardial performance index with conventional echocardiographic indices of systolic and diastolic function: a study in cardiac surgical patients. Echocardiography 24: 26-33, 2007.

PATEL N, MILLS JF, CHEUNG MM: Use of the myocardial performance index to assess right ventricular function in infants with pulmonary hypertension. Pediatr Cardiol 30: 133-137, 2009.

PATTONERI P, PELA G, MONTANARI E, PESCI I, MORUZZI P, BORGHETTI A: Evaluation of the myocardial performance index for early detection of mitoxantron-induced cardiotoxicity in patients with multiple sclerosis. Eur J Echocardiogr 8: 144-150, 2007.

PELTIER M, SLAMA M, GARBI S, ENRIQUEZ-SARANO ML, GOISSEN T, TRIBOUILLOY CM: Prognostic value of Doppler-derived myocardial performance index in patients with left ventricular systolic dysfunction. $A m J$ Cardiol 90: 1261-126, 2002.

PRATAP U, OFOE V, ONUZO O, KAPLANOVA J, FRANKLIN R, RADLEY-SMITH R, SLAVIK Z: Myocardial performance index in children with ventricular septal defect. Ces-slov Pediat 59: 271-273, 2004.

SENJU N, IKEDA S, KOGA S, MIYAHARA Y, TSUKASAKI K, TOMONAGA M, KOHNO S: The echocardiographic Tei-index reflects early myocardial damage induced by anthracyclines in patients with hematological malignancies. Heart Vessels 22: 393-397, 2007.

SHEEN CI, LAMPARELLI H, MILNE A, GREEN I, RAMAGE JK: Clinical features, diagnosis and outcome of acute portal vein thrombosis. Int $J$ Med 93: 531-534, 2000.

SNIDERMAN KW, SOS TA: Hepatic Schistosomiasis: A case with intrahepatic shunting and extrahepatic portal vein occlusion. Am J Roentgenol 130: 565-567, 1978.

TAKANO JS: Chapter 133: Advanced haemodynamic monitoring: Pulmonary artery and left atrial cathetrization. In: Essentials of Pediatric Intensive Care. DL LEVIN, FC MORRISS (eds), Churchill Livingstone, New York, 1997, pp 1234-1248.

TEI C, LING LH, OH JK, RODEHEFFER RJ, TAJIK J, SEWARD B: Evaluation of a new Doppler index of myocardial performance. J Am Soc. Echocardiograph 8: 357-366, 1995.

TEI C, DUJARDIN KS, HODGE DO, BAILEY KR, MCGOON MD, TAJIK AJ, SEWARD JB: Doppler echocardiographic index of global right ventricular function. J Am Soc Echocardiogr 9: 838-847, 1996.

TEI C, DUJARDIN KS, HODGE DO, KYLE RA, TAJIK AJ, SEWARD JB: Doppler index combining systolic and diastolic myocardial performance: clinical value in cardiac amyloidosis. $J$ Am Coll Cardiol 28: 658-664, 1996.

TEI C, NISCHIMURA RA, SEWARD JB, TAJIK AJ: Non-invasive Doppler-derived myocardial performance index correlation with simultaneous cardiac catheterisation measurements. J Am Soc Echocardiogr 10: 169-178, 1997.

TESHIMA K, ASANO K, IWANAGA K, KOIE H, UECHI M, KATO Y, KUTARA K, EDAMURA K, HASEGAWA A, TANAKA S: Evaluation of left ventricular Tei index (index of myocardial performance) in healthy dogs and dogs with tricuspid regurgitation. J Vet Med Sci 69: 117-123, 2007.

TRESKA V, KUNTSCHER V, MOLACEK J, KOBR J, RACEK J, TREFIL L: Can ischemia- reperfusion syndrome in transplanted kidneys procedure from non-heart-beating donors be influenced by adding selenium into the reperfusion solution? An experimental study. Transplant Proc 35: 3125-3127, 2003.

YACOUB S, BIRKS EJ, SLAVIK Z, HENEIN M: Early detection of myocardial dysfunction in Chagas disease using novel echocardiographic indices. Trans R Soc Trop Med Hyg 98: 527-534, 2003.

WILLIAMS RV, RITTER S, TANI Y, PAGOTTO LT, MINICVH LL: Quantitative assessment of ventricular function in children with single ventricle using the Doppler myocardial performance index. Am J Cardiol 86: 1106-1110, 2000 . 